Çukurova Üniversitesi Mühendislik Mimarlık Fakültesi Dergisi, 29(2), 141-148 ss., Aralık 2014

Çukurova University Journal of the Faculty of Engineering and Architecture, 29(2), pp. 141-148, December 2014

\title{
İpliği Boyalı Pamuklu Kumaşların Boyutsal Değişimi Üzerine Bir Araştırma
}

\author{
Füsun DOBA KADEM ${ }^{* 1}$, R. Tuğrul OĞULATA ${ }^{1}$ \\ ${ }^{l}$ Ç.Ü., Mühendislik Mimarlık Fakültesi, Tekstil Mühendisliği Bölümü, Adana \\ Geliş tarihi: 10.11.2014 Kabul tarihi: 25.12.2014
}

\section{Özet}

Bu çalışmada farklı konstrüksiyonlarda dokunmuş pamuklu kumaşlar işletme şartlarında üretilmiş, daha sonra bu kumaşlara ön terbiye yapılmıştır. Kumaşların, standartlar esas alınarak yıkama ve buhar sonrası boyutsal değişimleri tespit edilmiştir. Elde edilen sonuçlar değerlendirilerek boyutsal değişimler yorumlanmıştır.

Anahtar Kelimeler: Boyutsal stabilite, Buhar çekmesi, Pamuklu dokuma kumaş

\section{A Research on Dimensional Changes of Yarn Dyed Cotton Fabrics}

\begin{abstract}
In this research, woven fabrics in different constructions were produced in a Tekstil Company, then pretreatment processes were applied to these fabrics. The dimensional changes after washing and steam application of these fabrics were determined experimentaly according to relevant standarts and the shrinkage results were evaluated.
\end{abstract}

Keywords: Dimensional stability, Steam shrinkage, Cotton woven fabric.

\footnotetext{
* Yazışmaların yapılacağı yazar: Füsun DOBA KADEM, Ç.Ü. Mühendislik Mimarlık Fakültesi, Tekstil Mühendisliği Bölümü, Adana, efsun72@ cu.edu.tr
} 


\section{GİRIŞ}

Pamuklu dokuma kumaşların fiziksel ve performans özelliklerinin deneysel olarak belirlendiği, deneysel sonuçların istatistiksel analizle değerlendirildiği bir çok bilimsel eser bulunmaktadır.

Higgins ve Diğerleri [1], bezayağı dokuma kumaşlar, poplin numuneleri ve çarşaflık kumaşlar üzerine yıkamanın etkisi inceledikleri çalışmada, çeşitli ev tipi yıkamaların (uygulamada kullanılan) boyutsal stabilite ve buruşma üzerine etkisi ve bezayağı pamuklu dokuma kumaşlarda diğer fiziksel özelliklere etkisini hem boyutsal stabilite hem buruşma-etkisiyle ve buruşma direnci apresi olmaksızın sistematik olarak incelemiştir. Uygun standart test metotları ile en-boy çekmesi, en ve boydaki çarpıklık, buruşma, tüm numunelerin kütlesi, yoğunluk alanı, atkı ve çözgü iplik çapları belirlenmiş, buruşmazlık bitim işleminin, kumaş yapısındaki bağımlı değişkenlere etkisi incelenmiştir. Bağımlı değerler için uzunluk çekmesi, genişlik çekmesi, en ve boydaki çarpıklık, buruşma değerlendirme derecesi, alan yoğunluğundaki değişim ve atkı ipliği çapındaki değişimin, aynı kumaşın numuneleri ayrı yıkandıklarında benzer ve tekrar elde edilebilir sonuçları ortaya koyduğu gözlenmiştir. Çalışmada her ne kadar deterjan kullanımı sabit oranda tutulsa da deterjanın, farklı kumaş yapıları ve buruşma direncini nasıl etkilediğini belirlemek de gerekli görülmüştür. Deterjan kullanımının, en ve boydan çekmeyi biraz artırdığı gözlenmiş olup, bu değişimin boydan çekmede $\% 3,6$ dan $\% 4,5$ 'e enden çekmede \%2,3'ten \%3,4'e ulaştı̆̆ görülmüştür. Deterjan kullanımının alan yoğunluğundaki değişim üzerine etkisinin istatistiksel analizi ise, alan yoğunluğunun deterjan kullanımından etkilendiğini göstermiştir. Yapılan çalışma sonucunda, pamuklu kumaşların boyca ve ence çekmezlik seviyesinin, en ve boydaki çarpıklık seviyesinden genel olarak daha düşük olduğu ve dokunmuş kumaşların çekmezliğinin, ilk yıkamada periyodu süresince en fazla olduğu tespit edilmiştir. Doba Kadem, ipliği boyalı pamuklu gömleklik kumaşlarda fiziksel özellikler ve performans özelliklerinin belirlenmesi ve üretim öncesi tahminlenmesine yönelik ampirik eşitliklerin oluşturulması üzerine bir çalışma hazırlamıştır.

Doba Kadem, elde edilen deneysel sonuçlara SPSS paket programı kullanılarak bazı istatistiksel analiz tekniklerini (K-S testi, Runs testi, regresyon analizi, korelasyon analizi) uygulamış ve böylece üretim öncesi tahminlemeye yönelik fiziksel ve performans özellikleriyle ilgili eşitlikler belirlemiştir [2]. Doba Kadem ve Oğulata, pamuklu ipliği boyalı dokuma kumaşlarda iplik numarası, çözgü ve atkı sıklığı, gramaj, kumaş kalınlığı, örgü raporu olarak bazı fiziksel özellikleri deneysel olarak belirlemişler, istatistiksel analizle korelasyon katsayısı yüksek ampirik eşitlikler elde etmişlerdir [3]. Doba Kadem ve Oğulata, ipliği boyalı pamuklu kumaşlarda kopma ve yırtılma mukavemetlerinin regresyon analizi ile tahminlenmesi [4,5], kumaş konstrüksiyonun boncuklanma ve aşınma ile kütle kaybının etkilerinin araştırılması [6] üzerine çalışmalar yapmışlardır.

\section{MATERYAL VE METOT}

\subsection{Materyal}

$\mathrm{Bu}$ çalışma kapsamında toplam 72 adet pamuklu dokuma kumaş, seçilmiş bir işletmenin desteği ile üretilmiş ardından numunelere bir terbiye işletmesinde, yakma ve haşıl sökme ön terbiye işlemleri uygulanmıştır. Çözgü ve atkı sıklıkları farklı, iplik numaraları ve örgü türleri farklı pamuklu kumaşlar, farklı konstrüksiyonlarda üretilerek yıkama ve buhar sonrası boyutsal değişimleri incelenmiştir.

Çizelge 1'de bezayağ 1 örgü için verilen parametreler, dimi $(2 / 2 \mathrm{Z}$ dimi) ve panama $(2 / 2)$ örgü türlerinde de aynı şekilde olmak üzere toplam 72 adet kumaş, işletme şartlarında üretilmiş ve standart şartlarda kondüsyonlama [7] sonrası ilgili standartlara göre test edilmiştir. Doba Kadem ve Oğulata, bu kumaşların fiziksel özelliklerinin tespit edilmesi ve elde edilen deneysel değerlerin kullanılarak ampirik bağıntıların oluşturulması üzerine bir çalışma hazırlamışlardır [3]. 
Çizelge 1. Deneysel çalışma için bezayağı örgüde kumaş konstrüksiyon özellikleri

\begin{tabular}{|c|c|c|c|c|}
\hline Örgü türü & $\begin{array}{c}\text { iplik no } \\
(\mathrm{Ne})\end{array}$ & $\begin{array}{c}\text { Çözgü skklı̆̆ } \\
\text { (tel/cm) }\end{array}$ & $\begin{array}{c}\text { Atkı skklı̆ } 1 \\
\text { (tel/cm) }\end{array}$ & $\begin{array}{c}\text { Numune } \\
\text { No }\end{array}$ \\
\hline \multirow{24}{*}{ Bezayağı $(1 / 1)$} & \multirow{9}{*}{$\begin{array}{c}\text { Penye, } \\
50 / 1\end{array}$} & \multirow{3}{*}{56} & 34 & 1 \\
\hline & & & 30 & 2 \\
\hline & & & 26 & 3 \\
\hline & & \multirow{3}{*}{48} & 34 & 4 \\
\hline & & & 30 & 5 \\
\hline & & & 26 & 6 \\
\hline & & \multirow{3}{*}{40} & 34 & 7 \\
\hline & & & 30 & 8 \\
\hline & & & 26 & 9 \\
\hline & \multirow{6}{*}{$\begin{array}{c}\text { Penye, } \\
40 / 1\end{array}$} & \multirow{3}{*}{45} & 27 & 10 \\
\hline & & & 24 & 11 \\
\hline & & & 20 & 12 \\
\hline & & \multirow{3}{*}{40} & 27 & 13 \\
\hline & & & 24 & 14 \\
\hline & & & 20 & 15 \\
\hline & \multirow{9}{*}{$\begin{array}{l}\text { Penye, } \\
30 / 1\end{array}$} & \multirow{3}{*}{38} & 30 & 16 \\
\hline & & & 25 & 17 \\
\hline & & & 20 & 18 \\
\hline & & \multirow{3}{*}{33} & 30 & 19 \\
\hline & & & 25 & 20 \\
\hline & & & 20 & 21 \\
\hline & & \multirow{3}{*}{27} & 30 & 22 \\
\hline & & & 25 & 23 \\
\hline & & & 20 & 24 \\
\hline
\end{tabular}

\subsection{Metot}

\subsubsection{Buhar Sonrası Boyut Değişimi Tayini (WIRA Buhar Stabilitesi)}

Buhar ortamında serbest halde duran kumaşın çekmesini belirlemek için uygulanan bu yöntemde BS 4323 standard1 [8] esas alınarak numuneler test edilmiştir. Şekil 1'de buhar sonu boyut değişiminin tayin edildiği wira cihazı görülmektedir. Kapalı bir odada buhara maruz kalmış kumaş numunelerinin çekmezliğini belirlemek için uygulanan bu testle buhar sonrası boyut değişimi uzama ise + , çekme ise - olarak doğrudan yüzde (\%) şeklinde değerlendirilmektedir. Hem uzama hem de çekmenin ölçüm aralığı wira cetvelinde \%10'a kadardır.

\subsubsection{Yıkamadan Sonra Boyut Değişimi (Sanfor Tayini)}

Çalışmada kullanılan kumaşların yıkamadan sonra boyut değişimi, TS 392 EN 25077 (ISO 6330 ile

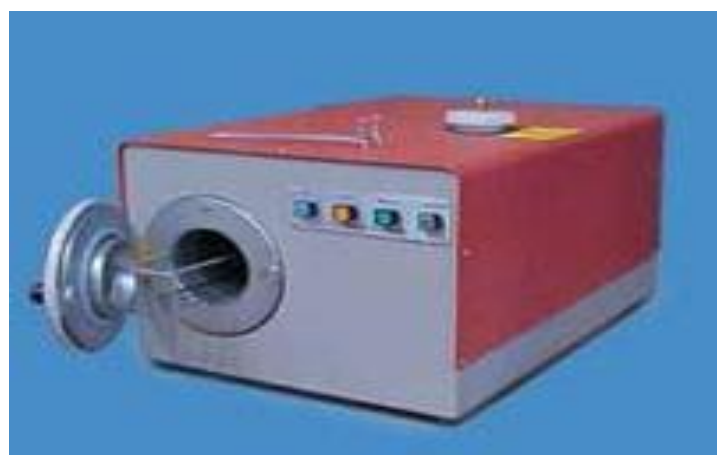

Şekil 1. WIRA cihazı [2]

uyumlu) $[9,10]$ standardı esas alınarak yapılmıştır. Yıkamadan çıkan numuneler, tumble dry tip kurutma makinasında 60 dakika sıcak, 5 dakika soğuk kurutmaya tabi tutulmuş ve kurutma sonras1 serbest ortamda 4 saat standart atmosfer şartlarında kondüsyona bırakılmıştır. Kondüsyonlanan numuneler, sanfor cetveli ile ölçülerek, atkı ve çözgü yönünde çekme (veya uzama) \% olarak ölçülmüştür (Şekil 2).

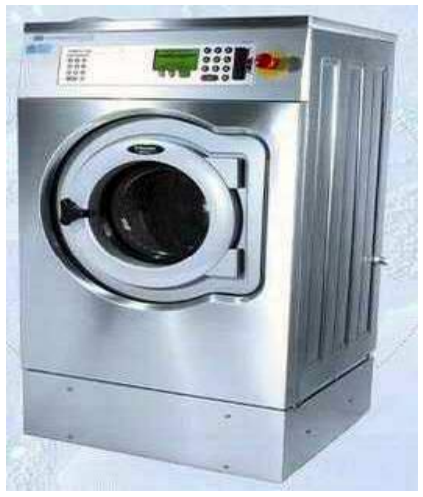

Şekil 2. Wascator [2]

\section{ARAŞTIRMA SONUÇLARI VE BULGULAR}

\subsection{Boyutsal Değişim (Yıkamadan Sonra ve Buhar Sonrası Boyut Değişimi) Değerlendirmesi}

Haş1l sökme ve yakma ön terbiye işlemleri görmüş pamuklu kumaşlara uygulanan yıkama ve 
buhar sonrası boyut değişimleri atkı ve çözgü doğrultuları için tespit edilmiş ve ölçüm sonuçlarının ortalamaları Çizelge 2,3 ve 4 'te verilmiştir. Çizelge 1'de farklı iplik numaralarında ve farklı sıklıklarda dokunan kumaş konstrüksiyon özellikleri için bezayağı örgüde üretilen toplam 24 kumaşın yıkama ve buhar sonrası boyut değişimi Çizelge 2'de görülmektedir.

Çizelge 2. Bezayağı kumaşların yıkama ve buhar sonrası boyut değişimi [2]

\begin{tabular}{|c|c|c|c|c|}
\hline \multirow{2}{*}{$\begin{array}{c}\text { Numune } \\
\text { no }\end{array}$} & \multicolumn{2}{|c|}{$\begin{array}{c}\text { Yıkamadan sonra boyut } \\
\text { değişimi (\%) }\end{array}$} & \multicolumn{2}{c|}{$\begin{array}{c}\text { Buhar sonrası boyut değişimi } \\
\text { (\%) }\end{array}$} \\
\cline { 2 - 5 } & Çözgü (-) & Atkı (+) & Çözgü (-) & Atkı (+) \\
\hline 1 & 9,67 & 0,75 & 2,38 & 0,63 \\
\hline 2 & 11,00 & 0,92 & 2,00 & 0,55 \\
\hline 3 & 9,50 & 1,17 & 2,50 & 0,66 \\
\hline 4 & 11,25 & 0,75 & 2,11 & 1,48 \\
\hline 5 & 11,00 & 1,17 & 2,25 & 1,03 \\
\hline 6 & 14,17 & 2,00 & 2,48 & 1,80 \\
\hline 7 & 9,67 & 2,58 & 2,10 & 1,45 \\
\hline 8 & 10,00 & 1,42 & 1,54 & 1,98 \\
\hline 9 & 9,58 & 1,50 & 1,55 & 1,50 \\
\hline 10 & 10,17 & 2,17 & 2,58 & 0,69 \\
\hline 11 & 12,00 & 2,00 & 1,58 & 1,03 \\
\hline 12 & 10,33 & 2,67 & 2,08 & 0,58 \\
\hline 13 & 11,67 & 1,83 & 1,63 & 1,15 \\
\hline 14 & 12,33 & 2,50 & 1,73 & 1,28 \\
\hline 15 & 11,50 & 2,50 & 1,60 & 1,34 \\
\hline 16 & 11,83 & 2,93 & 2,20 & 0,65 \\
\hline 17 & 12,50 & 1,25 & 2,10 & 0,66 \\
\hline 18 & 12,33 & 0,58 & 1,64 & 1,40 \\
\hline 19 & 11,25 & 2,25 & 1,58 & 1,50 \\
\hline 20 & 12,50 & 1,42 & 1,50 & 1,23 \\
\hline 21 & 13,83 & 0,98 & 1,58 & 1,60 \\
\hline 22 & 9,67 & 0,50 & 1,60 & 1,06 \\
\hline 23 & 10,83 & 0,50 & 1,83 & 2,14 \\
\hline 24 & 14,08 & 1,90 & 1,74 & 1,40 \\
\hline
\end{tabular}

Çizelge 3. Dimi kumaşların yıkama ve buhar sonrası boyut değişimi [2]

\begin{tabular}{|c|c|c|c|c|}
\hline \multirow{2}{*}{$\begin{array}{c}\text { Numune } \\
\text { no }\end{array}$} & \multicolumn{2}{|c|}{$\begin{array}{c}\text { Yıkamadan sonra boyut } \\
\text { değisimi (\%) }\end{array}$} & \multicolumn{2}{c|}{$\begin{array}{c}\text { Buhar sonrası boyut değişimi } \\
\text { (\%) }\end{array}$} \\
\cline { 2 - 5 } & Cözgü (-) & Atkı (+) & Cözgü (-) & Atkı (+) \\
\hline 1 & 9,33 & 1,17 & 1,21 & 1,00 \\
\hline 2 & 9,00 & 1,67 & 1,35 & 0,98 \\
\hline 3 & 9,67 & 2,17 & 2,05 & 1,40 \\
\hline 4 & 9,25 & 1,33 & 1,43 & 1,11 \\
\hline 5 & 11,08 & 2,50 & 1,53 & 2,36 \\
\hline 6 & 10,50 & 3,33 & 2,48 & 1,78 \\
\hline 7 & 9,42 & 3,42 & 1,33 & 2,11 \\
\hline 8 & 8,83 & 1,00 & 0,95 & 1,00 \\
\hline 9 & 8,42 & 1,00 & 1,00 & 1,20 \\
\hline 10 & 9,83 & 3,90 & 1,01 & 1,01 \\
\hline 11 & 9,67 & 2,50 & 2,20 & 1,05 \\
\hline 12 & 9,17 & 2,83 & 1,70 & 1,30 \\
\hline 13 & 9,17 & 3,06 & 1,50 & 1,33 \\
\hline 14 & 9,00 & 4,00 & 1,63 & 1,50 \\
\hline 15 & 9,00 & 3,67 & 1,79 & 1,83 \\
\hline 16 & 10,67 & 0,75 & 1,06 & 1,30 \\
\hline 17 & 8,00 & 1,67 & 1,45 & 1,00 \\
\hline 18 & 9,50 & 2,17 & 1,36 & 1,43 \\
\hline 19 & 9,83 & 0,83 & 1,28 & 0,88 \\
\hline 20 & 11,83 & 1,77 & 1,56 & 1,00 \\
\hline 21 & 9,83 & 2,17 & 1,35 & 1,36 \\
\hline 22 & 8,58 & 3,50 & 1,10 & 0,90 \\
\hline 23 & 9,83 & 0,83 & 0,98 & 0,75 \\
\hline 24 & 11,42 & 2,50 & 1,40 & 0,89 \\
\hline
\end{tabular}

Çizelge 2, 3 ve 4'ten görüldüğü gibi değerlendirme sonuçlarında çözgü yönünde çekme (-) atk1 yönünde uzama $(+)$ olduğu tespit edilmiştir. Çalışmada kullanılan kumaşlara ön terbiye sonrasında sanforizasyon denilen ve mekanik bir bitim işlemi olan 'çekmezlik bitim işlemi' uygulanmamıştır. Dolayısıyla kumaşlarda yıkama sonrası boyut değişimi olması beklenen bir durumdur. Şekil 3 ve 4'te tüm kumaşların yıkamadan sonra çözgü ve atkı yönünde boyut değişimi, Şekil 5 ve 6 'da ise buhar sonrası çözgü ve atkı yönünde boyut değişimi görülmektedir.

Çizelge 4. Panama kumaşların yıkama ve buhar sonrası boyut değişimi [2]

\begin{tabular}{|c|c|c|c|c|}
\hline \multirow{2}{*}{$\underset{\text { nom. }}{\text { Num. }}$} & \multicolumn{2}{|c|}{$\begin{array}{l}\text { Yikamadan sonra } \\
\text { boyut değişimi }(\%)\end{array}$} & \multicolumn{2}{|c|}{$\begin{array}{c}\text { Buhar sonrası boyut } \\
\text { değişimi }(\%)\end{array}$} \\
\hline & Çözgü (-) & Atk1 (+) & Çözgü (-) & Atkı (+) \\
\hline 1 & 8,73 & 2,43 & 1,66 & 1,00 \\
\hline 2 & 8,50 & 2,67 & 1,11 & 1,38 \\
\hline 3 & 9,17 & 2,50 & 2,03 & 1,26 \\
\hline 4 & 10,33 & 1,23 & 1,13 & 1,05 \\
\hline 5 & 9,66 & 2,92 & 1,28 & 1,36 \\
\hline 6 & 10,25 & 2,83 & 1,78 & 1,89 \\
\hline 7 & 8,75 & 1,17 & 1,06 & 1,05 \\
\hline 8 & 8,67 & 0,75 & 0,58 & 1,08 \\
\hline 9 & 7,83 & 0,77 & 1,03 & 0,48 \\
\hline 10 & 9,00 & 4,17 & 1,70 & 1,25 \\
\hline 11 & 9,33 & 4,00 & 1,62 & 1,62 \\
\hline 12 & 9,17 & 4,06 & 2,13 & 1,25 \\
\hline 13 & 7,67 & 4,07 & 1,25 & 0,63 \\
\hline 14 & 8,33 & 4,33 & 1,20 & 1,23 \\
\hline 15 & 9,00 & 3,17 & 1,28 & 1,24 \\
\hline 16 & 8,50 & 1,75 & 1,41 & 0,78 \\
\hline 17 & 8,00 & 2,17 & 1,28 & 0,93 \\
\hline 18 & 9,50 & 2,50 & 1,21 & 1,45 \\
\hline 19 & 10,25 & 1,17 & 0,98 & 0,86 \\
\hline 20 & 8,17 & 2,17 & 1,39 & 0,88 \\
\hline 21 & 8,50 & 3,50 & 1,46 & 1,11 \\
\hline 22 & 7,67 & 2,58 & 0,68 & 0,48 \\
\hline 23 & 9,42 & 3,00 & 1,15 & 0,90 \\
\hline 24 & 11,92 & 3,17 & 0,90 & 0,90 \\
\hline
\end{tabular}

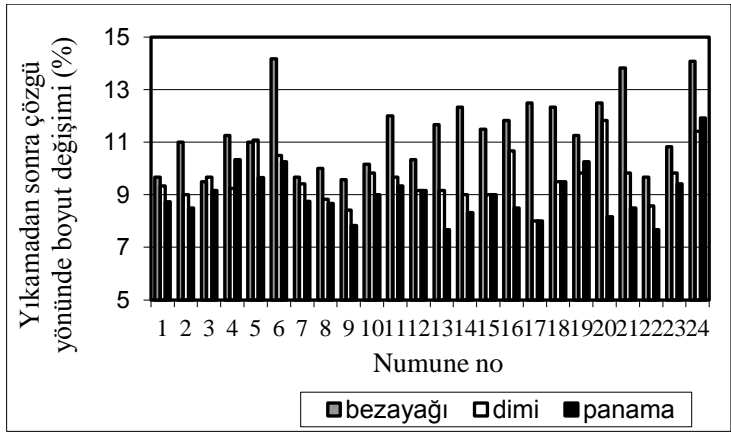

Şekil 3. Yıkamadan sonra çözgü yönünde boyut değişimi (çekme) [2] 


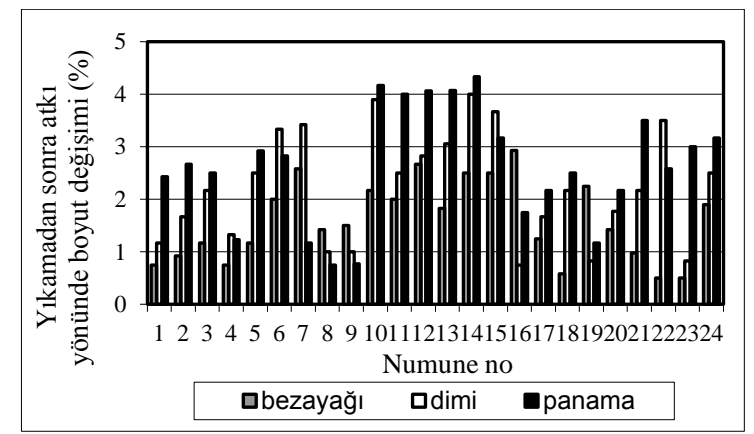

Şekil 4. Yıkamadan sonra atkı yönünde boyut değişimi (uzama) [2]

Yıkama işlemine tabi tutulan numunelerde, yıkama sırasında liflerdeki dolayısıyla ipliklerdeki enine kesit şişmesi kumaşlarda çekmeye, kısalmaya neden olmaktadır. Sulu ortamlardaki kesit şişmesi sonucu ipliklerde çap büyümesi olmakta, ipliklerin doku içinde birbiri üzerinden ve altından kat etmek

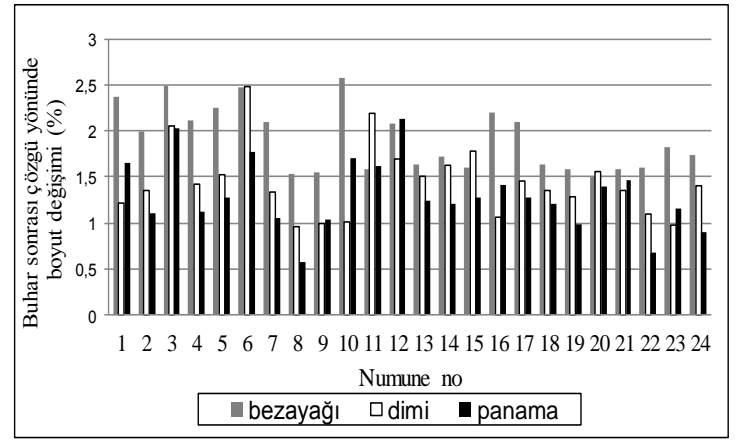

Şekil 5. Buhar sonrası çözgü yönünde boyut değişimi (çekme) [2]

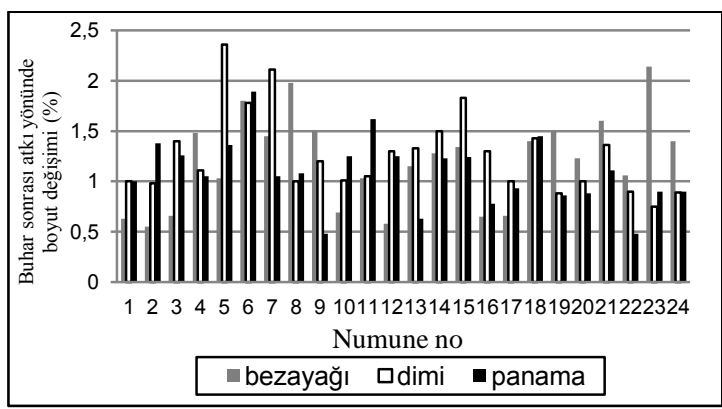

Şekil 6. Buhar sonrası atk1 yönünde boyut değişimi (uzama) [2] zorunda oldukları yol uzamakta ve dolayısıyla kumaşlarda enden boydan çekme, kisalma olmaktadır. Yıkamada oluşan bu durum daha sonraki kurutmada tekrar eski haline dönememektedir. $\mathrm{O}$ nedenle kesit şişmesi fazla olan pamuk gibi doğal lifler, diğer liflere göre daha çok çekmektedir. Kumaşların ön terbiye sonrasında örneğin haşıl sökmeden sonra kurutmasının yapılmasında, eğer ramöz gibi bir kurutma makinesi kullanılırsa, kurutmada ön beslemeli avanslı çalışmanın neticesinde atkıda uzama görülebilmektedir. Ayrıca mamul kumaş eni, istenilen enden az olursa (örneğin mamul eni $150 \mathrm{~cm}$ olsun ancak ölçülen en $143 \mathrm{~cm}$ olsun) ön terbiye sonrası kurutma yapılması gerektiğinden kurutma çıkışında eni değişmekte, daha sonra bu kumaşlara y1kamadan sonra çekme testi uygulandığında, uzama gösterebilmektedir [2]. En fazla bağlantı sayısına sahip bezayağı kumaşlarda çözgü yönünde çekme, genel olarak daha fazla çıkmıştır. Atkı yönünde ise uzama görülmüştür. Benzer şekilde buhar sonrası boyut değişiminde de, materyale buhar etkisiyle bir gevşeme sağlanmakta ve boyca uzama ya da çekme görülmektedir. wira testi, giysi imalatında buhar presi uygulandığında kumaş gevşeme çekmesini tahmin etmede önemli olan bir testtir. Normal olarak dokuma kumaşlar için \%2'ye kadar örme kumaşlar içinde \%3'e kadar çekme değerleri kabul edilmektedir [11]. Burada buhar sonu boyut değişimi, ham madde türü pamuk olduğu için yüksek değerlerde olmayıp, kabul edilebilir sınırlar içindedir.

\section{2. İstatistiksel Analiz Sonuçları ve Değerlendirme}

Bezayağ1, dimi ve panama örgüde fiziksel özellikler [3] kullanılarak buhar sonrası boyut değişimi için istatistiksel analiz sonucu elde edilen regresyon modellerinin eşitlikleri, Çizelge 5'te verilmiştir. $\mathrm{Bu}$ kapsamda, verilerin normal dağılıma uygunluğu ve rasgeleliği analizinden sonra çoklu regresyon analizi $[12,13]$ ile modeller oluşturulmuş ve elde edilen model eşitliklerine korelasyon analizi uygulanmıştır. Çizelgede yer alan semboller aşağıda listelenmiştir.

$\mathrm{n}$ : iplik numarası $(\mathrm{Ne})$

cs: çözgü sıklığı (tel/cm) 
as: atkı sıklığı (tel/cm)

k: kumaş kalınlığ 1 (mm)

wa:buhar sonrası atkı boyut değişimi

(\%) (atkı buhar stabilitesi)

wc: buhar sonrası çözgü boyut değişimi (\%)

(çözgü buhar stabilitesi)

Çizelge 5. İstatistiksel analizle elde edilen buhar stabilitesi eşitlikleri

\begin{tabular}{|c|c|}
\hline Elde edilen eşitlikler & $\begin{array}{c}\text { Korelasyon } \\
\text { katsayis! }\end{array}$ \\
\hline 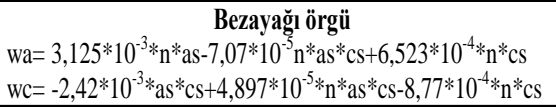 & $\begin{array}{c}0,63 \\
0,657\end{array}$ \\
\hline $\begin{array}{c}\text { Dimi örgü } \\
\text { wc }=-1,41 * 10^{-3} * a s * c s+6,28 * 10^{-5} * n * a s * c s-1,64 * 10^{-3} * n * c s \\
\text { wa }=1,589 * 10^{-3} * n * a s-4,88 * 10^{-5} n * a s * c s+1,075 * 10^{-3} * n * c s\end{array}$ & $\begin{array}{l}0,65 \\
0,51\end{array}$ \\
\hline $\begin{array}{l}\text { Panama örgü } \\
\text { wc }=-5,02 * 10^{-2} * \mathrm{cs}-2,133 * \mathrm{k}+5,391 * 10^{-2} * \text { as } \\
\text { wa }=3,954 * 10^{-2} * \mathrm{cs}+1,393 * \mathrm{k}-3,70 * 10^{-2} * \text { as }\end{array}$ & $\begin{array}{l}0,769 \\
0,661\end{array}$ \\
\hline
\end{tabular}

İstatistiksel analiz sonucu elde edilen eşitlikler önerilen eşitlikler olup, buradan hesaplanan değerlerin deneysel sonuçlar ile karşılaștırılması grafiklerle gösterilmiştir (Şekil 7-12). Şekillerde üç örgü türünde de wira ölçülen ( $\square$ işareti) ve hesaplanan (-işareti) değerleri ile gösterilmiş olup, korelasyon katsayısı yüksek olan wira değerlerinde ölçülen ve hesaplanan değerler birbirine yakınken, korelasyon katsayısı düşük olan performans özelliklerinde değerler arasında farklılıklar görülmektedir.

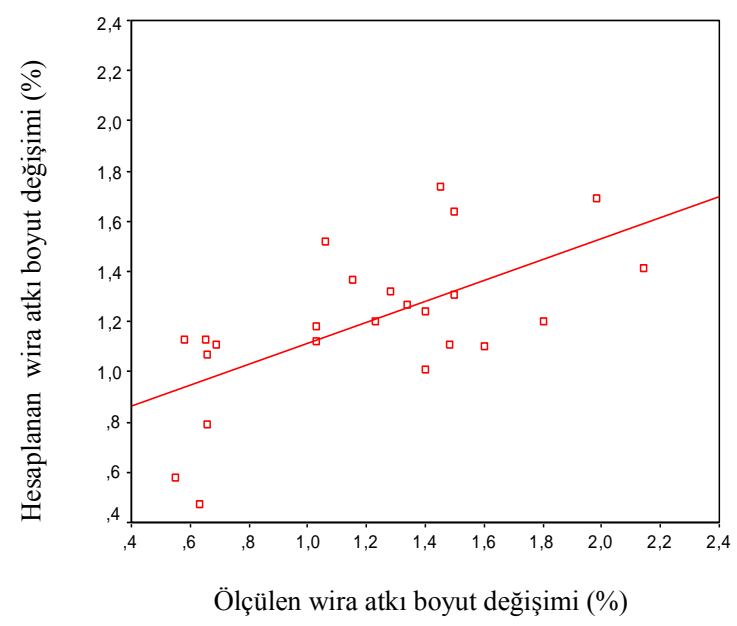

Şekil 7. Bezayağı örgüde wira atkı boyut değişimi

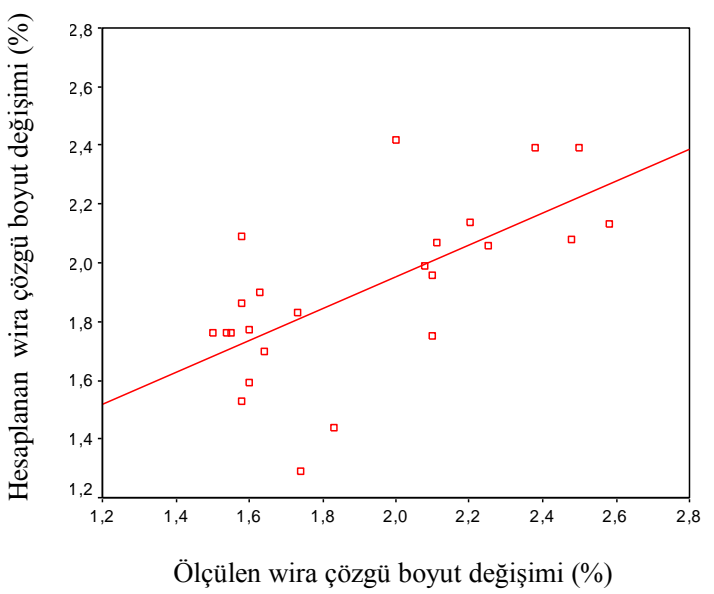

Şekil 8. Bezayağı örgüde wira çözgü boyut değişimi

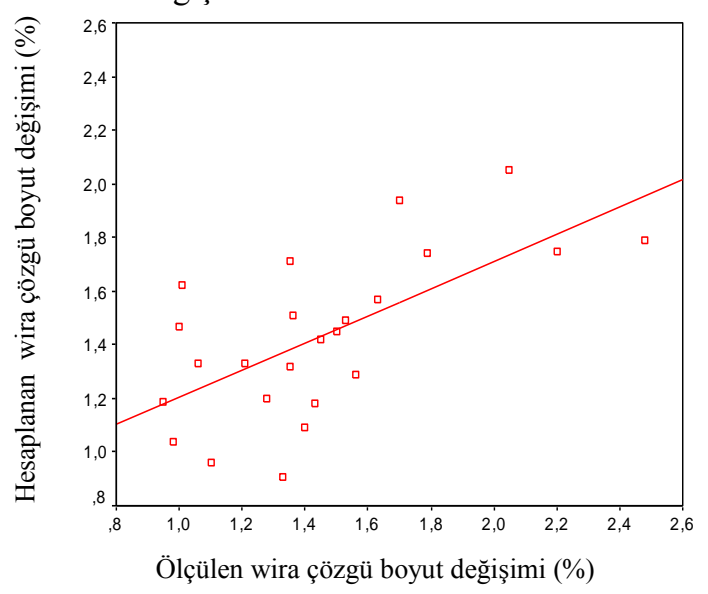

Şekil 9. Dimi örgüde wira çözgü boyut değişimi

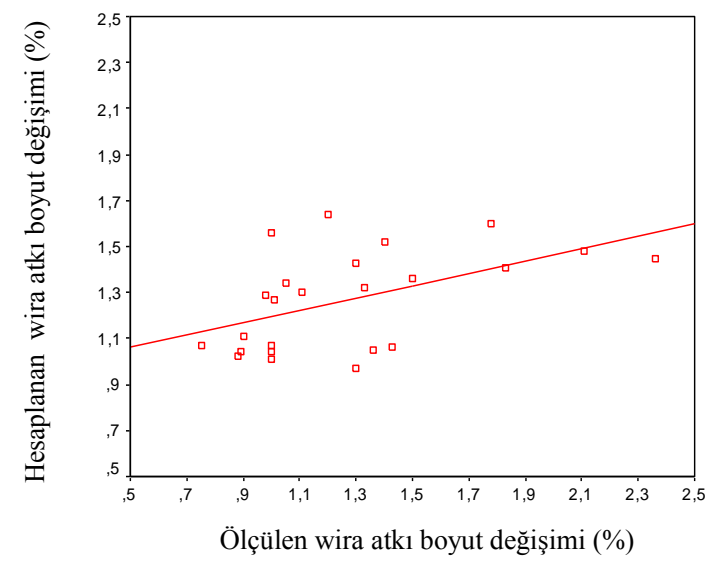

Şekil 10. Dimi örgüde wira atkı boyut değişimi 


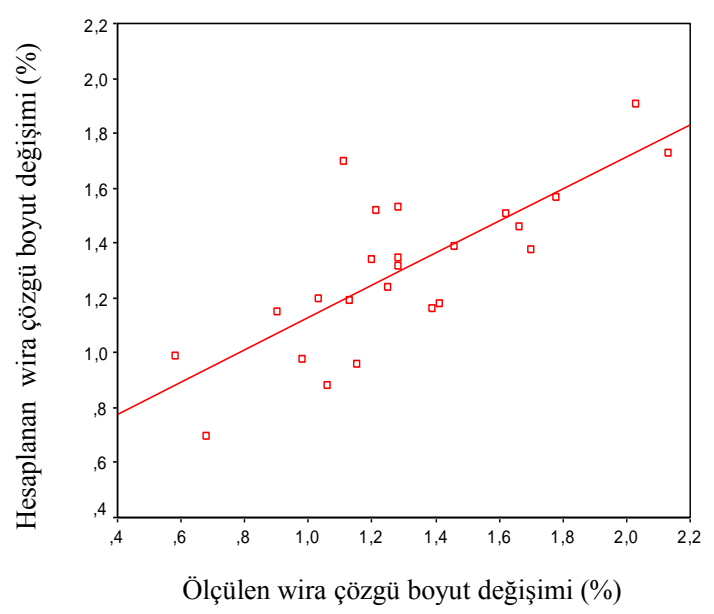

Şekil 11. Panama örgüde wira çözgü boyut değişimi

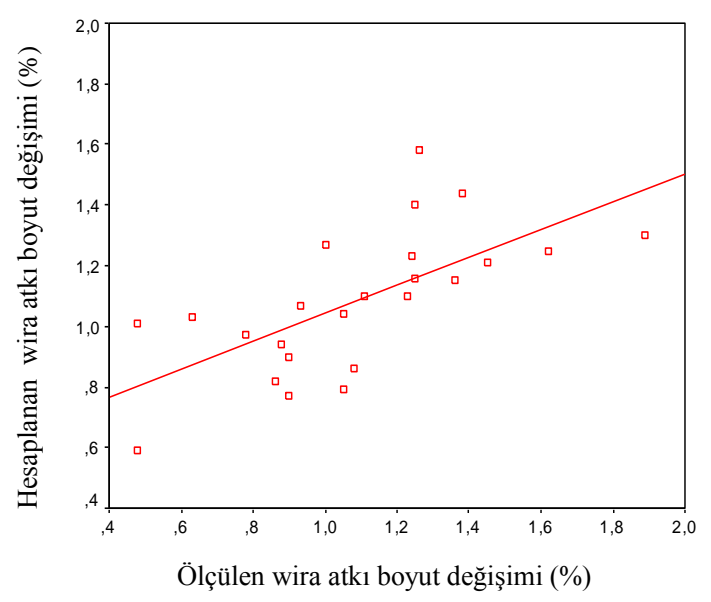

Şekil 12. Panama örgüde wira atkı boyut değişimi

\section{SONUÇ}

Çalışma kapsamında, farklı sıklıklardaki atkı ve çözgü ipliklerinden farklı örgülerde dokunmuş pamuklu kumaşların yıkama ve buhar sonrası boyut değişimi standartlara göre deneysel olarak belirlenerek, grafiksel ve istatistiksel olarak yorumlanmıştır. Yıkamadan sonra çözgü ve atkı yönünde boyut değişiminde tüm numunelerde çözgü yönünde çekme (-) atkı yönünde uzama (+) tespit edilmiştir. En fazla bağlantı sayısına sahip bezayağı kumaşlarda çözgü yönünde çekme, genel olarak daha fazla çıkmıştır. Yıkama işlemine tabi tutulan numunelerde, yıkama sirasinda liflerdeki dolayısıyla ipliklerdeki enine kesit şişmesi kumaşlarda çekmeye kısalmaya neden olmaktadır. Ayrıca mamul kumaş eni, istenilen enden az olursa ön terbiye sonras1 kurutma yapılmas1 gerektiğinden kurutma çıkışında eni değişmekte, daha sonra bu kumaşlara y1kamadan sonra çekme testi uygulandığında, uzama gösterebilmektedir. Benzer şekilde buhar sonrası boyut değişiminde de, materyale buhar etkisiyle bir gevşeme sağlanmaktadır, burada çözgü boyunca çekme atkı boyunca uzama görülmüştür. Normal olarak dokuma kumaşlar için \%2'ye kadar örme kumaşlar içinde \%3'e kadar çekme değerleri kabul edilmektedir. Burada buhar sonu boyut değişimi, ham madde türü pamuk olduğu için yüksek değerlerde olmayıp, kabul edilebilir sınırlar içindedir. Buhar sonrası atk1 ve çözgüde boyut değişimi ile ilgili olarak yapılan istatistik analizle, atkı ve çözgü sıklığı, kalınlık ve iplik numarası fiziksel özellikleri ile tahminlemeye yönelik ampirik bağıntılar oluşturulmuştur.

\section{$\underline{\text { Öneriler }}$}

- Çalışma, daha farklı iplik numarası ve örgüler gibi daha geniş yelpazede konstrüksiyonlar için denenebilir.

- Çalı̧̧mada replikasyon sayısı 1'dir. Replikasyon sayısının artırılması ile (örneğin 10 gibi) elde edilecek kumaşların bu çalışma gibi deneysel ve istatistiksel analizi yapılarak daha iyi sonuçlara ulaşılabilir.

- Çalışmada numunelere ön terbiye işlemi olarak yakma ve haşıl sökme işlemi uygulanmıştı. Ön terbiye işlemi sonrası, bu özellikteki kumaşlara apre uygulanarak bu çalışmadaki tespit edilen yıkama ve buhar sonrası boyutsal değişimler seçilmiş bir apre işlemi uygulanması sonrasında da tespit edilip karşılaştırılmaları yapılabilir.

\section{TEŞEKKÜR}

$\mathrm{Bu}$ çalışmanın yürütülmesinde verdiği destekten dolayı, Çukurova Üniversitesi BAP Koordinasyon 
Birimi'ne teşekkür ederiz (Proje No: MMF. 2005. D1).

\section{KAYNAKLAR}

1. Higgins, L., Anand S.C., Holmas D.A., Hall M.E., 2003. Effects of Various Home Laundering Practices on the Dimensional Stability, Part I: Wrinkling and Other Properties of Plain Woven Cotton Fabrics. Textile Research Journal, Vol.73, No:4, 357-366.

2. Doba Kadem F., 2007. İpliği Boyalı Pamuklu Kumaşlarda Bazı Fiziksel Özelliklerin Seçilmiş Performans Özellikleriyle İlişkisinin Araştırılması, Doktora Tezi, Çukurova Üniversitesi Fen Bilimleri Enstitüsü Tekstil Mühendisliği Anabilim Dalı.

3. Doba Kadem F., Oğulata R.T., 2010. İpliği Boyalı Pamuklu Dokuma Kumaşlarda Fiziksel Özelliklerin Regresyon Analizi, Çukurova Üniversitesi Mühendislik-Mimarlık Fakültesi Dergisi, Cilt:25, Say1:1-2, 125-133, Haziran-Aralık

4. Oğulata R.T., Doba Kadem F., 2008. Boyalı İpliklerden Üretilen Farklı Konstrüksiyonlardaki $\% 100 \quad$ Pamuklu Kumaşlarda Kumaş Kopma Mukavemetinin Regresyon Analizi ile Tahminlenmesi, Tekstil ve Konfeksiyon, Y1l:18, Say1 3, 185-190, Temmuz-Eylül.

5. Doba Kadem F., Oğulata R.T., 2009. Boyalı İpliklerden Üretilen Farkl Konstrüksiyonlardaki Pamuklu Kumaşlarda Kumaş Yırtılma Mukavemetinin Regresyon Analizi, Tekstil ve Konfeksiyon, Y11:19, Say1 2, 97-101, Nisan-Haziran.

6. Doba Kadem F., Oğulata R.T., 2014. İpliği Boyalı Pamuklu Kumaşlarda Kumaş Konstrüksiyonunun Boncuklanma ve Aşınmaya Etkisinin Araştırılması, Çukurova Üniversitesi Mühendislik-Mimarlık Fakültesi Dergisi, Cilt:29, Sayı:1, 89-97, Haziran

7. TS 240 EN 20139, 1995. TekstilKondüsyonlama ve Deneyler için Standart Atmosfer Şartları. Türk Standartları Enstitüsü.

8. BS 4323, 2006. Determination of Dimensional Change of Fabrics Induced by Free Steam,
Kıvanç Tekstil Mamul Kalite Kontrol
Laboratuarı Föyü.

9. TS 392 EN 25077, 1996. Tekstil MamulleriY1kama ve Kurutmadan Sonra Boyut Değişmesinin Tayini, Türk Standartları Enstitüsü.

10.BS EN ISO 6330, 2001. Textile Domestic Washing and Drying Procedures for Textile Testing.

11. Demir A., Günay M., 1999. Tekstil Teknolojisi Elyaf, İplik, Dokuma, Örme, Halı, Dikiş İplikleri, Forbes Publication, Dördüncü Baskı, $368 \mathrm{~s}$.

12. Akgül A., Çevik O., 2003. İstatistiksel Analiz Teknikleri, SPSS'te İşletme Uygulamaları. Emek Ofset, Ankara, $456 \mathrm{~s}$.

13. Kalaycı Ş., 2006. SPSS Uygulamalı Çok Değişkenli İstatistik Teknikleri. Baran Ofset, İkinci Bask1, $426 \mathrm{~s}$. 